\title{
The role of designomics in jewellery design
}

\begin{abstract}
Designomics, a new terminology is derived from the two words, álesignôand áconomicsô The value of a particular design is determined by the theories of economy in this influence. This research bares the objectives of developing guidelines and criteria for designers to adapt the concept of designomics in the jewellery industry. The aim of this study is to inspire design skills towards enhancing entrepreneurial leadership. In addition, the researchers develop a method to ensure the attainment of the designomicôs investigation. The designers will be able to contribute their value within the business sector. With a more extensive understanding of the theory, we can address the economic contribution of the design for business managers to understand.
\end{abstract}

Keyword: Designomics; Jewellery; Design 